\title{
The Impact of Nutritional Status and Complete Blood Count Parameters on Clinical Outcome in Geriatric Critically III Patients
}

\author{
Abdulkerim Yildiz $^{\mathrm{a}, \mathrm{b}, \mathrm{d}}$, Ali Yigit ${ }^{\mathrm{b}}$, Ali Ramazan Benli ${ }^{\mathrm{c}}$
}

\begin{abstract}
Background: The geriatric population in intensive care units (ICUs) has recently increased. The aim of this study was to analyse the impact of initial complete blood count (CBC)-related parameters and nutritional status on morbidity and mortality in geriatric ICU patients.

Methods: A retrospective analysis was made of geriatric patients admitted to our tertiary adult ICU for 1 year. Patients with a length of stay (LOS) of $<48 \mathrm{~h}$, with hematological malignancy or age $<65$ years age were excluded from the study. Initial albumin level was considered to reflect nutritional status. The prevelance and risk factors of mortality and microbiologically documented infection (MDI) were analysed.

Results: The study included a total of 243 patients with a mean age of $78.96 \pm 6.62$ years. The overall mortality rate was $40.7 \%$. The most common cause for admission was acute respiratory failure and sepsis $(17.2 \%$ vs. $16.8 \%)$. The most common MDI sources were lower respiratory tract, bloodstream, and urinary tract infections. Patients with thrombocytopenia on admission had a higher mortality rate than patients with normal platelet count $(\mathrm{P}=0.019)$. The initial albumin level of non-survivors was significantly lower than that of survivors $(\mathrm{P}=0.001)$. There was a significant negative correlation between albumin level and $\operatorname{LOS}(\mathrm{r}=-0.157 ; \mathrm{P}=0.000)$. Patients with hypoalbuminemia (albumin $<3.2 \mathrm{~g} / \mathrm{dL}$ ) at the time of diagnosis had higher mortality, LOS and MDI rates than those with normal albumin levels $(\mathrm{P}<0.05)$. There was no significant relationship between any other $\mathrm{CBC}$-related parameter and infection and mortality $(\mathrm{P}>0.05)$.
\end{abstract}

Conclusions: Thrombocytopenia and hypoalbuminemia may be con-

Manuscript submitted May 2, 2018, accepted May 10, 2018

aDepartment of Hematology, University of Health Sciences, Diskapi Yildirim Beyazit, Training and Research Hospital, Ankara, Turkey

${ }^{b}$ Department of Internal Medicine, KBU Karabuk Research and Educational Hospital, Karabuk, Turkey

'Department of Family Medicine, Karabuk University, Medical Faculty, Karabuk, Turkey

${ }^{\mathrm{d} C}$ Corresponding Author: Abdulkerim Yildiz, Department of Hematology, Diskapi Yildirim Beyazit Training and Research Hospital, Ankara, Turkey.

Email: akerim@hotmail.com

doi: https://doi.org/10.14740/jocmr3461w sidered as major risk factors for morbidity and mortality in critically ill elderly patients.

Keywords: Albumin; Geriatric patients; Criticall ill; Mortality; Infection

\section{Introduction}

The number of elderly patients in intensive care units (ICUs) has shown a significant increase in recent years. Patients aged $>65$ years account for $42 \%-52 \%$ of all admissions to the ICU [1]. Therefore, there is a need for prognostic markers or scoring systems specific to the geriatric population. Complete blood count $(\mathrm{CBC})$ parameters and related parameters are already known and remain an interesting topic for researchers. Thrombocytopenia, which is defined as a platelet count of $<$ $150,000 / \mu \mathrm{L}$, is one of the most common laboratory abnormalities seen in critically ill patients admitted to ICU, with reported incidence ranging from $13 \%$ to $60 \%$ [2-7]. Thrombocytopenia can be a result of increased (non-immune or immune) platelet destruction, hemodilution, platelet sequestration (as in hypersplenism), or decreased platelet production $[8,9]$. Many previous studies have reported that thrombocytopenia in ICU is associated with prolonged hospital stay and reduced survival $[2-7,9,10]$.

The nutritional status of the geriatric population, even in ICU, is very important in the prediction of prognosis. While various parameters have been used to assess the nutritional status of geriatric patients, serum albumin is one of the most commonly used parameters. It has been shown to be a sensitive indicator of protein deficiency malnutrition, which is not always associated with low body weight. Patients are considered to be malnourished when serum albumin concentration is $<3.5 \mathrm{~g} /$ $\mathrm{dL}[1,11,12]$. Hypoalbuminemia has been shown to be associated with increased mortality and morbidity rates in samples of elderly persons [13-15]. It has also been reported to be related with poor clinical outcomes in critically ill adults $[16,17]$.

Platelet count and albumin levels are not used in the Acute Physiology and Chronic Health Evaluation II (APACHE II) score, which is the most commonly used prognostic score in ICU patients. Furthermore, it is still not clearly known whether hypoalbuminemia on ICU admission is a definite predictor of 
increased mortality and whether it affects outcomes in geriatric patients. Therefore, the aim of this study was to evaluate the CBC-related parameters and hypoalbuminemia and investigate whether they are associated with poor clinical outcomes in geriatric ICU patients.

\section{Matrials and Methods}

A retrospective analysis was made of patients admitted to the Medical ICU of Karabuk University Training and Research Hospital from January 2015 to January 2016. Patients with a length of stay (LOS) $<48 \mathrm{~h}$, with hematological malignancy, or aged $<65$ years were excluded from the study. The study included a total of 243 patients.

Evaluation was made of the demographic information, laboratory test results, APACHE II scores, diagnosis at the time of admission, LOS in ICU and mortality rate of the patients by reviewing the medical records and hospital database. The leukocyte count $\left(/ \mathrm{mm}^{3}\right)$, lymphocyte count $\left(/ \mathrm{mm}^{3}\right)$, platelet count $\left(/ \mathrm{mm}^{3}\right), \mathrm{Hb}$ level $(\mathrm{g} / \mathrm{dL})$ and mean platelet volume (MPV) were recorded from the CBC. The platelet to lymphocyte ratio (PLR) value was calculated using these measurements. According to our hospital biochemistry laboratory database, normal platelet level range is $140,000-450,000\left(/ \mathrm{mm}^{3}\right)$, and normal albumin level range is $3.2-4.8 \mathrm{~g} / \mathrm{dL}$. Microbiologically documented infection (MDI) was defined as the presence of symptoms or signs of inflammation at an anatomic site where pathogens were recovered from the affected site. For the analysis of mortality, the study population was separated into two groups as survivors and non-survivors. For the analysis of MDI episodes, the study population was separated into two groups as patients with any episode of MDI and those without any MDI episode.

SPSS Statistics 19 Software (IBM, Armonk, NY, USA) was used for statistical analysis. In the comparison of variables distributed homogeneously, the $t$-test was used for parametric variables and the Chi-square test was used for non-parametic variables. For variables not showing homogeneous distribution, the Mann Whitney U test was used. Data were expressed as mean \pm standard deviation (SD) and median (minimummaximum) values. Multiple logistic regression analyses were used to determine the risk factors for mortality and CDI. A value of $\mathrm{P}<0.05$ was accepted as statistically significant.

\section{Compliance with ethical standards}

All procedures performed in the study were in accordance with the ethical standards of the institutional and/or national research committee and with the 1964 Helsinki Declaration and its later amendments or comparable ethical standards.

\section{Results}

Baseline characteristics of patients are shown in Table 1. The patients comprised a total of 243 patients with a mean age of $78.96 \pm 6.62$ years, mean LOS of $10.23 \pm 8.68$ days and mor-
Table 1. Baseline Characteristics of Patients

\begin{tabular}{ll}
\hline & All $(\mathbf{n}=\mathbf{2 4 3}), \mathbf{n}(\mathbf{\%})$ \\
\hline $\begin{array}{l}\text { Age (year) }( \pm \mathrm{SD}) \\
\text { Gender }\end{array}$ & $78.96 \pm 6.62$ \\
$\quad$ Male & $104(42.8 \%)$ \\
$\quad$ Female & $139(57.2 \%)$ \\
Number of comorbidities (median) & $3.0(1.0-8.0)$ \\
APACHE II (median) & $26.0(9.0-47.0]$ \\
Length of stay (mean \pm SD) & $10.23 \pm 8.68$ \\
Microbiologically documented infection & \\
$\quad$ Yes & $59(24.2 \%)$ \\
$\quad$ No & $184(75.8 \%)$ \\
Final status & $144(59.3 \%)$ \\
$\quad$ Survivor & $99(40.7 \%)$ \\
$\quad$ Nonsurvivor &
\end{tabular}

APACHE II: acute physiology and chronic health evaluation score II.

tality rate of $40.7 \%$. The incidence of thrombocytopenia at the time of admission was $26.3 \%(64 / 243)$. ICU mortality was $53.1 \%$ in thrombocytopenic patients and $36.3 \%$ in non-thrombocytopenic patients. Patients with initial thrombocytopenia had a higher mortality rate than patients with normal platelet count $(\mathrm{P}=0.019)$. Compared with survivors, non-survivors had a lower albumin level on admission to ICU $(\mathrm{P}=0.001)$. Patients with albumin $<3.2 \mathrm{~g} / \mathrm{dL}$ on admission had a higher mortality rate than those with albumin $\geq 3.2 \mathrm{~g} / \mathrm{dL}(\mathrm{P}=0.007)$. There was a significant negative correlation between albumin level and $\operatorname{LOS}(\mathrm{r}=-0.157 ; \mathrm{P}=0.000)$. No significant relationship was determined between other $\mathrm{CBC}$-related parameters and mortality and LOS. Parameters and their relationship with mortality are shown in Table 2 and Figure 1.

There were determined to be 89 MDI episodes in 59 patients. The most common infection sources were lower respiratory tract, bloodstream, and urinary tract. Most MDI episodes were caused by Gram-positive agents (48.3\%). Methicillinresistant coagulase-negative staphylococci (MRCoNS) was the most frequently seen agent. A total of 31 (34.8\%) MDI episodes were caused by Gram-negative agents, with Escherichia coli (E.coli) determined as the most isolated agent in eight episodes. There were 15 fungal MDI episodes, with Candida albicans isolated in 10 episodes, mostly in urine cultures. The MDI pathogens are shown in Table 3. Patients with MDI had lower albumin levels on admission to ICU than patients without MDI $(\mathrm{P}=0.004)$. Patients with hypoabuminemia (albumin $<3.2 \mathrm{~g} /$ $\mathrm{dL}$ ) had higher MDI rates than those with albumin $\geq 3.2 \mathrm{~g} / \mathrm{dL}$ $(\mathrm{P}=0.06)$. No significant relationship was determined between other CBC-related parameters and MDI. Parameters and their relationship with MDI are shown in Table 4 and Figure 2.

\section{Discussion}

A previous prospective cohort study reported that irrespective 
Table 2. Parameters and Their Relationship With Mortality

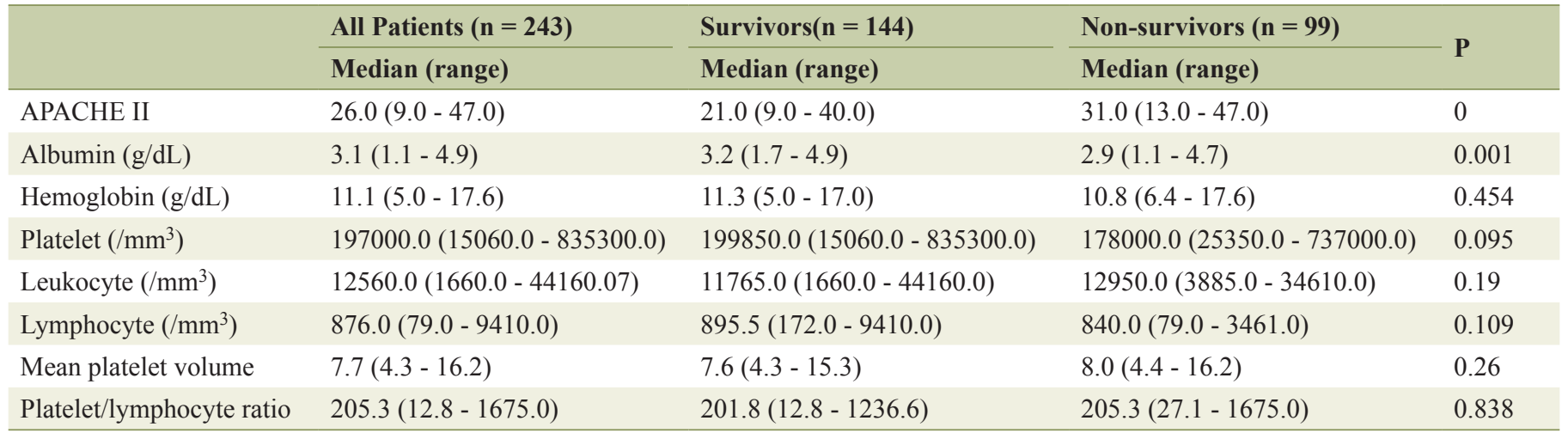

APACHE II: acute physiology and chronic health evaluation score II.
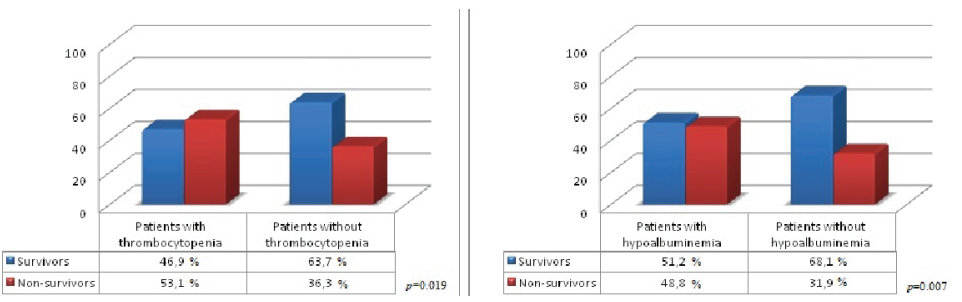

Figure 1. The relationship of platelet count and albumin level at the time of admission with motality.

of initial thrombocytopenia values, the occurence of thrombocytopenia during ICU stay can also predict poor prognosis in adult ICU patients [8]. Another prospective study revealed that a drop in platelet counts of $\geq 30 \%$, but not thrombocytopenia per se, is independently associated with ICU mortality [18]. Another study showed both low and declining platelet counts

Table 3. Pathogens of Microbiologically Documented Infection Episodes

\begin{tabular}{|ll}
\hline & All $(\mathbf{n}=\mathbf{8 9}) \mathbf{( \% )}$ \\
\hline Gram positive bacteria & $43(48.3 \%)$ \\
\hline MRCoNS & 14 \\
Corynebacterium striatum & 11 \\
Enterococcus faecium & 6 \\
Others & 12 \\
Gram negative bacteria & $31(34.8 \%)$ \\
\hline Escherichia coli & 8 \\
Pseudomonas aeruginosa & 6 \\
Klebsiella Pneumoniae & 5 \\
Acinetobacter baumannii & 5 \\
Others & 7 \\
Fungal agents & $15(16.9 \%)$ \\
Candida albicans & 10 \\
Candida tropicalis & 4 \\
Candida parapsilosis & 1 \\
\hline
\end{tabular}

MRCoNS: methicillin-resistant coagulase-negative staphylococci. are markers of the severity of critical patients and are directly related to prognosis and mortality of patients in ICU [6]. In the current study, the incidence of thrombocytopenia at the time of admission was $26.3 \%$ and mortality was $53.1 \%$ in these patients. The incidence was lower but the mortality rate was slightly higher than rates reported in recent studies. The incidence of thrombocytopenia has been reported as 37\% - 44\% and mortality as $31 \%-44 \%$ in past studies $[6,18]$.

Another significant point is the relationship between thrombocytopenia and the infection rates and outcomes in ICU patients. In a study of 931 patients with sepsis in 2016, Claushuis et al demonstrated that platelet counts $<50,000$ were associated with increased cytokines and endothelial-cell activation and impaired vascular integrity. It was suggested that thrombocytopenia on admission is associated with higher mortality during sepsis, independent of disease severity [10]. Another study analyzed the relationship between thrombocytopenia and BSI in ICU patients and suggested that thrombocytopenia, whether present at the onset of a BSI or developing later during the clinical course, indicates unfavorable outcomes [19]. In the current study, no significant relationship was determined between $\mathrm{CBC}$ and related parameters and MDI.

One of the largest cohort studies analyzed the relationship between serum albumin level and all-cause mortality in an elderly population and evaluated the role of albumin level in combination with physical disability status in predicting mortality. In both genders, there was determined to be an increase in mortality rate proportional to decreasing albumin level. Hypoalbuminemia $<3.5 \mathrm{~g} / \mathrm{dL}$ was found to be associated with a significantly increased risk of mortality and it was suggested that serum albumin level is an independent risk factor for all- 
Table 4. Parameters and Their Relationship With Microbiologically Documented Infection

\begin{tabular}{|c|c|c|c|c|}
\hline & \multirow{2}{*}{$\begin{array}{l}\text { All Patients }(n=243) \\
\text { Median (range) }\end{array}$} & \multirow{2}{*}{$\begin{array}{l}\text { Patients without MDI }(n=184) \\
\text { Median (range) }\end{array}$} & \multirow{2}{*}{$\begin{array}{l}\text { Patients with MDI }(\mathrm{n}=\mathbf{5 9}) \\
\text { Median (range) }\end{array}$} & \multirow{2}{*}{$\mathbf{P}$} \\
\hline & & & & \\
\hline APACHE II & $26.0(9.0-47.0)$ & $23.0(9.0-44.0)$ & $31.0(16.0-47.0)$ & 0 \\
\hline Hemoglobin (g/dL) & $11.1(5.0-17.6)$ & $11.3(5.0-17.2)$ & $10.8(6.4-17.6)$ & 0.573 \\
\hline Leukocyte $\left(/ \mathrm{mm}^{3}\right)$ & $12560.0(1660.0-44160.0)$ & $12280.0(1660.0-44160.0)$ & $12950.0(5420.0-3743.0)$ & 0.487 \\
\hline Mean platelet volume & $7.7(4.3-16.2)$ & $7.6(4.3-16.2)$ & $7.9(4.4-13.3)$ & 0.538 \\
\hline Platelet/lymphocyte ratio & $205.3(12.8-1675.0)$ & $195.8(12.8-1675.0)$ & $219.8(27.1-1102.7)$ & 0.398 \\
\hline
\end{tabular}

APACHE II: acute physiology and chronic health evaluation score II; MDI: microbiologically documented infection.

cause mortality in the elderly [13]. In a study of 15,111 patients aged $>40$ years, Herrmann FR et al studied the serum albumin level within 48 h of hospitalization for acute illness and found that patients with low serum albumin levels had higher mortality rates, longer hospital stays, and were readmitted sooner and more frequently than patients with normal albumin levels. It was suggested that the serum albumin level was a non-specific marker and a stronger predictor of mortality, LOS, and readmission than age [15]. A similar result was reported in a retrospective study of 113 patients aged $>65$ years who were admitted to the anesthesia ICU. In that study, a low albumin level $(\leq 3 \mathrm{mg} / \mathrm{dL}$ ) was accepted as an indicator of nutritional status and found to be associated with higher mortality together with a negative correlation with APACHE score. It was suggested that age in itself did not predict mortality in the elderly [1]. In a study of mixed-case critically ill patients, lower albumin level was found to be an independent predictor of mortality [17].

Serum albumin levels are important not only in ICU patients but also in the healthy geriatric population. A prospective study of healthy elderly individuals reported that serum albumin levels decreased with increasing age in both genders, and this association was independent of health status. In addition, after adjustments for age, gender and lifestyle factors such as smoking, exercise and alcohol consumption, lower albumin levels were determined to be related to higher mortality. It was therefore concluded that serum albumin levels could be a predictor for subclinical disease in the healthy elderly population [14].

Hypoalbuminemia in ICU has also been analyzed in pediatric patients and found to be associated with higher mortal-

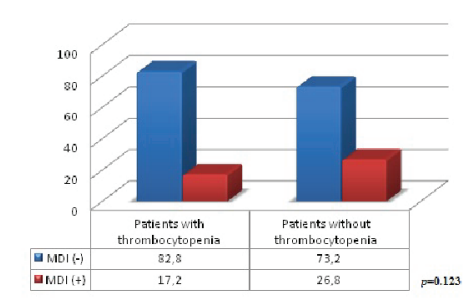

ity, a longer LOS in PICU, and prolonged ventilator use [20]. Another study of 271 pediatric patients revealed that hypoalbuminemia on admission to PICU is associated with higher 60day mortality, longer duration of mechanical ventilation, and lower probability of ICU discharge [21].

To the best of our knowledge, there has been no previous study which has evaluated the direct relationship between albumin levels and infection episodes in geriatric ICU patients. However, in a study analysing hypoalbuminemia in septic patients, low serum albumin levels and APACHE II scores were identified as independent risk factors for mortality. The 28-day survival rate was lower for patients with serum albumin $<2.9$ $\mathrm{g} / \mathrm{dL}$ than for patients with serum albumin at or above this level [22]. Another finding reported by two previous studies is that the serum albumin level on admission is a good prognostic marker in community acquired pneumonia [23, 24]. In the current study, patients with lower albumin levels at the time of diagnosis had more MDI episodes.

However, it is doubtful whether albumin replacement could be useful for decreasing mortality and morbidity especially in geriatric patients. In a meta-analysis by Vincent JL et al, hypoalbuminemia was found to be a potent, dose-dependent independent predictor of poor outcome in acute illness. Lower albumin concentration was significantly related to higher mortality, morbidity, prolonged ICR and hospital stay. An association between hypoalbuminemia and poor outcome was found to be independent of both nutritional status and inflammation. The result of that study suggested that complication rates may be reduced when the serum albumin level attained during albumin administration exceeds $3.0 \mathrm{~g} / \mathrm{dL}$ [16].

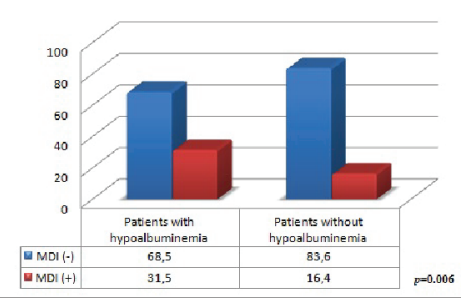

Figure 2. The relationship of platelet count and albumin level at the time of admission with microbiologically documented infection. MDI: microbiologically documented infection. 


\section{Conclusions}

In conclusion, this study supports that there is an association of thrombocytopenia and hypoalbuminemia with adverse outcomes in critically ill elderly patients. Patients with hypoalbuminemia tend to have higher morbidity and mortality rates. A combined measurement of albumin level and platelet count reveals a strong gradient in the risk of morbidity and mortality, and may help to identify a high-risk group of geriatric patients who could be targeted for more careful and closer follow-up in ICU.

\section{Conflict of Interest}

None.

\section{References}

1. Onal O, Ozgun G. Comparison of the Course and Prognosis of Geriatric Patients Admitted to the Intensive Care Unit According to BMI and Albumin Values. Anesth Pain Med. 2016;6(1):e32509.

2. Chakraverty R, Davidson S, Peggs K, Stross P, Garrard $\mathrm{C}$, Littlewood TJ. The incidence and cause of coagulopathies in an intensive care population. Br J Haematol. 1996;93(2):460-463.

3. Cawley MJ, Wittbrodt ET, Boyce EG, Skaar DJ. Potential risk factors associated with thrombocytopenia in a surgical intensive care unit. Pharmacotherapy. 1999;19(1):108113.

4. Baughman RP, Lower EE, Flessa HC, Tollerud DJ. Thrombocytopenia in the intensive care unit. Chest. 1993;104(4):1243-1247.

5. Crowther MA, Cook DJ, Meade MO, Griffith LE, Guyatt GH, Arnold DM, Rabbat CG, et al. Thrombocytopenia in medical-surgical critically ill patients: prevalence, incidence, and risk factors. J Crit Care. 2005;20(4):348-353.

6. Khurana D, Deoke SA. Thrombocytopenia in critically ill patients: clinical and laboratorial behavior and its correlation with short-term outcome during hospitalization. indian J Crit Care Med. 2017;21(12):861-864.

7. Hui P, Cook DJ, Lim W, Fraser GA, Arnold DM. The frequency and clinical significance of thrombocytopenia complicating critical illness: a systematic review. Chest. 2011;139(2):271-278.

8. Vanderschueren S, De Weerdt A, Malbrain M, Vankersschaever D, Frans E, Wilmer A, Bobbaers H. Thrombocytopenia and prognosis in intensive care. Crit Care Med. 2000;28(6):1871-1876.

9. Thachil J, Warkentin TE. How do we approach thrombocytopenia in critically ill patients? Br J Haematol. 2017;177(1):27-38.

10. Claushuis TA, van Vught LA, Scicluna BP, Wiewel MA, Klein Klouwenberg PM, Hoogendijk AJ, Ong DS, et al. Thrombocytopenia is associated with a dysregulat- ed host response in critically ill sepsis patients. Blood. 2016;127(24):3062-3072.

11. Bohl DD, Shen MR, Hannon CP, Fillingham YA, Darrith B, Della Valle CJ. Serum Albumin Predicts Survival and Postoperative Course Following Surgery for Geriatric Hip Fracture. J Bone Joint Surg Am. 2017;99(24):2110-2118.

12. Gibbs J, Cull W, Henderson W, Daley J, Hur K, Khuri SF. Preoperative serum albumin level as a predictor of operative mortality and morbidity: results from the National VA Surgical Risk Study. Arch Surg. 1999;134(1):36-42.

13. Corti MC, Guralnik JM, Salive ME, Sorkin JD. Serum albumin level and physical disability as predictors of mortality in older persons. JAMA. 1994;272(13):1036-1042.

14. Klonoff-Cohen H, Barrett-Connor EL, Edelstein SL. Albumin levels as a predictor of mortality in the healthy elderly. J Clin Epidemiol. 1992;45(3):207-212.

15. Herrmann FR, Safran C, Levkoff SE, Minaker KL. Serum albumin level on admission as a predictor of death, length of stay, and readmission. Arch Intern Med. 1992;152(1):125-130.

16. Vincent JL, Dubois MJ, Navickis RJ, Wilkes MM. Hypoalbuminemia in acute illness: is there a rationale for intervention? A meta-analysis of cohort studies and controlled trials. Ann Surg. 2003;237(3):319-334.

17. Quispe EA, Li XM, Yi H. Comparison and relationship of thyroid hormones, IL-6, IL-10 and albumin as mortality predictors in case-mix critically ill patients. Cytokine. 2016;81:94-100.

18. Strauss R, Wehler M, Mehler K, Kreutzer D, Koebnick C, Hahn EG. Thrombocytopenia in patients in the medical intensive care unit: bleeding prevalence, transfusion requirements, and outcome. Crit Care Med. 2002;30(8):1765-1771.

19. Vandijck DM, Blot SI, De Waele JJ, Hoste EA, Vandewoude KH, Decruyenaere JM. Thrombocytopenia and outcome in critically ill patients with bloodstream infection. Heart Lung. 2010;39(1):21-26.

20. Kittisakmontri K, Reungrongrat S, Lao-Araya M. Hypoalbuminaemia at admission predicts the poor outcomes in critically ill children. Anaesthesiol Intensive Ther. 2016;48(3):158-161.

21. Leite HP, Rodrigues da Silva AV, de Oliveira Iglesias SB, Koch Nogueira PC. Serum albumin is an independent predictor of clinical outcomes in critically ill children. Pediatr Crit Care Med. 2016;17(2):e50-57.

22. Yin M, Si L, Qin W, Li C, Zhang J, Yang H, Han H, et al. Predictive value of serum albumin level for the prognosis of severe sepsis without exogenous human albumin administration. J Intensive Care Med. 2016:885066616685300.

23. Viasus D, Garcia-Vidal C, Simonetti A, Manresa F, Dorca J, Gudiol F, Carratala J. Prognostic value of serum albumin levels in hospitalized adults with community-acquired pneumonia. J Infect. 2013;66(5):415-423.

24. Lee JH, Kim J, Kim K, Jo YH, Rhee J, Kim TY, Na SH, et al. Albumin and $\mathrm{C}$-reactive protein have prognostic significance in patients with community-acquired pneumonia. J Crit Care. 2011;26(3):287-294. 